\title{
Educação Física e Ciências do Esporte no tempo presente: defender vidas, afirmar as ciências
}

Fernando Mascarenhas ${ }^{\mathrm{a}}$ (D), Ari Lazzarotti Filho ${ }^{\mathrm{b}}$ (D), Lauro Casqueiro Viannac (i)

Abrimos este volume 43 da Revista Brasileira de Ciências do Esporte (RBCE) com editorial cujo título reproduz o tema do XXII Congresso Brasileiro de Ciências do Esporte (CONBRACE) e IX Congresso Internacional de Ciências do Esporte (CONICE), com realização prevista para o período estendido de 12 de setembro a 17 de dezembro próximos.

Defender vidas e afirmar as ciências nunca foi tão necessário ante o clima de desinformação que favorece a disseminação de negacionismos encampados por governos com políticas escancaradamente anticientíficas. Mesmo num contexto de emergência na saúde pública, não se reconhece a importância da ciência e das universidades como instituições profundamente envolvidas e essenciais na busca de soluções e realizações de combate à pandemia. Evidências desse processo são os sucessivos cortes no financiamento à pesquisa e desmoralização das universidades, comprometendo a capacidade de resposta do país à Covid-19 (Mascarenhas et al., 2020).

Lamentamos e nos solidarizamos aos amigos e familiares das 250 mil vítimas da epidemia no país (em 24/2/2021). Se o Brasil tivesse tido um desempenho apenas "mediano" no combate ao vírus, a julgar pela média mundial, mais de 150 mil vidas teriam sido salvas (em 21/1/2021), afirma Hallal (2021). Para além de omissões na coordenação nacional para organizar o combate à pandemia e prover recursos, o mapeamento e análise das normas jurídicas de resposta à Covid-19 no Brasil, produzido pelo Centro de Estudos e Pesquisas de Direito Sanitário da Universidade de São Paulo (USP), revela a existência de uma estratégia institucional de propagação do Coronavírus promovida pelo Governo Federal. Foram mais de 3 mil atos normativos editados pela União em 2020 contrários a recomendação de entes técnicos. Dentre inúmeras medidas nocivas apontadas, estão aquelas que dificultaram a implementação do distanciamento social e estimularam o uso de drogas sem comprovação científica (Conectas Direitos Humanos, 2021).

"Defender vidas e afirmar as ciências constituem exigências do tempo presente, tempo em que ações de ensino, de pesquisa e de extensão necessitam estar plenamente comprometidas com a preservação da Vida" (CBCE, 2020).

Para a Educação Física e Ciências do Esporte, isso deve se refletir em compromissos éticos da formação, da intervenção profissional, do fazer científico, da produção e difusão do conhecimento, da prática social e pedagógica com os direitos sociais, o desenvolvimento humano, a cidadania e o meio ambiente.

Reunindo pesquisadores e pesquisadoras da área, o Colégio Brasileiro de Ciências do Esporte (CBCE) possui uma tradição democrática e luta pela por um mundo com justiça e equidade social, afirmando as ciências como estruturantes da diversidade que nos constitui como humanidade. Maior expressão desta história e compromisso é o próprio CONBRACE/CONICE, um dos maiores e mais importantes congressos da Educação Física e Ciências do Esporte realizados no Brasil e América Latina, com o compartilhamento de conhecimentos produzidos a partir de diferentes olhares e concepções, de distintas abordagens, temas, objetos e problematizações. Assim, em setembro, quando o CBCE completará seus 43 anos, frente ao obscurantismo que assola o país, nossa comunidade

\footnotetext{
aUniversidade de Brasília, Faculdade de Educação Física. Brasília, DF, Brasil.

bUniversidade Federal de Goiás, Faculdade de Educação Física e Dança. Goiânia, GO, Brasil.

'Universidade de Brasília, Faculdade de Educação Física. Brasília, DF, Brasil.
}

\footnotetext{
*Autor correspondente:

Fernando Mascarenhas

E-mail: fernandom@unb.br
} 
será mais uma vez desfiada a propor ideias e ações para superar as circunstâncias que põem em risco a vida e a própria ideia de civilização (CBCE, 2020).

Por sua vez, a RBCE, também editada pelo CBCE, como periódico científico mais longevo da Educação Física brasileira, também possui uma história de retaguarda crítica aos processos de governamento que perpassam a área, buscando sempre contribuir para o aumento da liberdade acadêmica, a formação profissional e ética. (Almeida et al., 2018).

Hoje, impactada fortemente pelo corte no financiamento da ciência, a RBCE se vê diante das mesmas dificuldades, desafios e dilemas que vêm marcando seu longo tempo de vida, o que envolve sua sustentabilidade econômica, gestão e avaliação (Almeida et al., 2015, 2018).

A sustentabilidade econômica, frente a escassez de recursos e editais de apoio a publicação de periódicos por parte das agências de fomento é hoje uma questão de sobrevivência para nosso periódico. Para se ter uma ideia, o principal programa de fomento ao periodismo científico brasileiro, o Programa Editorial do Conselho Nacional de Desenvolvimento Científico e Tecnológico (CNPq) publicou sua última Chamada Pública para novos financiamentos em 2019. A RBCE teve sua proposta recusada, assim como várias outras revistas regularmente incentivadas. N área da Educação, por exemplo, nenhum dos periódicos que concorreram à Chamada foi contemplado (ANPEd, 2019). O fato é que a descontinuidade do financiamento público torna a RBCE dependente dos recursos próprios do CBCE e das Taxas de Processamento de Artigos (APCs - Article Processing Charges). Esta é uma realidade a ser discutida junto a nossa comunidade.

$\mathrm{Na}$ esteira deste processo, está também o fim coproducão da RBCE com a Elsevier, em 2019, motivado tanto pelo reposicionamento da empresa no mercado editorial mundial, como pelos altos custos de contrato o que, num contexto de crise no financiamento público da pesquisa, onerava pesadamente as finanças do CBCE. (Mascarenhas et al. 2019). Se por um lado, tal movimento trouxe relativo alívio financeiro para nossa associação, por outro, impactou sobremaneira a gestão do trabalho editorial. Avançamos na parceria SciELO-ScholarOne quanto ao processamento e avaliação dos manuscritos no ano que passou. Todavia, enfrentamos grandes dificuldades frente às demandas de produção editorial, o que envolve os processos de revisão, formatação, tradução, diagramação e envio para publicação dos manuscritos aprovados, serviços contratados que não foram realizados a contento. Problema também ligado ao contexto da pandemia da Covid-19. Com a contratação de nova editora (Editora Cubo, ver: https://www. editoracubo.com.br//, tais dificuldades foram superadas.

Quanto à avaliação dos periódicos, em especial, aquela organizada a partir da CAPES, é importante dizer que a sobrevalorização dos indicadores bibliométricos internacionais de fluxo de informação, que privilegiam as revistas de língua inglesa, neste momento, é reforçada a partir da proposta do Novo Qualis. Tal proposta ameaça a sustentabilidade e, até mesmo, a sobrevivência dos periódicos nacionais. Essa é uma preocupação que se expressa pelos recentes posicionamentos do Fórum Nacional de Editores de Periódicos Científicos da Educação Física (FNEPCEF), da Associação Brasileira de Editores Científicos (ABEC) e do Comitê Consultivo do Programa Scielo. Os periódicos de qualidade do país cumprem o papel de comunicar pesquisas que são de escopo ou interesse nacionais, dessa forma, os resultados dessas pesquisas são mais comunicados por periódicos editados nacionalmente. Nessa condição, não concorrem e são complementares às pesquisas comunicadas em periódicos publicados no exterior. Por isso a necessidade de valorização e fomento dos periódicos nacionais (Revista Movimento, 2019; Rocha, 2020).

Ainda que a RBCE possua um baixo percentual de manuscritos publicados na língua inglesa, bem como impacto bibliométrico aquém daqueles definidos pela CAPES através do Qualis, sua história - que se relaciona com a própria história da Educação Física e Ciências do Esporte no Brasil - e legitimidade acadêmico-científica conquistada junto aos pares nacionais constituem a base de sua qualidade, até porque qualidade é diferente de impacto. Ademais, seu ingresso e permanência na Coleção SciELO Brasil atestam um modelo aperfeiçoado continuamente nas funções de indexação, publicação. Nossa Revista está submetida a uma metodologia avançada de avaliação de periódicos, similar ou mais abrangente que a dos índices Web of Science (WoS) e Scopus, obedecendo as boas práticas editoriais.

Nessa linha, frente a atualização dos critérios SciELO Brasil visando o alinhamento da coleção de seus periódicos com as práticas de comunicação da ciência aberta, anunciamos que, ainda neste ano, implementaremos mudanças na política editorial da RBCE, com: a inclusão da modalidade de preprint no fluxo de comunicação científica da revista; o compartilhamento dos dados, códigos, métodos e outros materiais utilizados e resultantes das pesquisas que geralmente ficam subjacentes nos textos dos artigos publicados no nosso periódico; e a abertura progressiva do processo de avaliação dos manuscritos por pares. Com essas mudanças, seguimos buscando qualificar a RBCE.

Boa Leitura!

\section{REFERÊNCIAS}

Almeida, Bassani JJ, Richter AC, Invernizzi L, Vaz AF. Revista Brasileira de Ciências do Esporte: encerrando um ciclo editorial. Motrivivência. 2018;30(54):74-89. http://dx.doi. org/10.5007/2175-8042.2018v30n54p74.

Almeida, Bassani JJ, Vaz AF. Vicissitudes de uma história da RBCE: 35 anos de editoração científica (1979-2013). Motrivivência. 2015;26(46):135-53. http://dx.doi. org/10.5007/2175-8042.2015v27n46p135. 
Associação Nacional de Pós-Graduação e Pesquisa em Educação - ANPEd. Nota da ANPEd sobre os cortes no financiamento do programa Editorial do CNPq e outras chamadas [Internet]. Rio de Janeiro: ANPEd; 2019 [citado 2021 Fev 21]. Disponível em: https://anped.org.br/news/ nota-da-anped-sobre-os-cortes-no-financiamento-doprograma-editorial-do-cnpq-e-outras-chamadas

Colégio Brasileiro de Ciências do Esporte-CBCE. Educação Física e Ciências do Esporte no tempo presente: defender vidas, afirmar as ciências [Internet]. Porto Alegre: CBCE; 2020 [citado 2021 Fev 25]. Disponível em: https://conbrace.org.br

Conectas Direitos Humanos. Mapeamento e análise das normas jurídicas de resposta à Covid-19 no Brasil. Boletim Direitos na Pandemia [Internet]. 2021 [citado 2021 Fev 21];10. Disponível em: https://www.conectas.org/publicacoes/ download/boletim-direitos-na-pandemia-no-10

Hallal PC. SOS Brazil: science under attack. Lancet. 2021;397(10272):373-4. https://doi.org/10.1016/S01406736(21)00141-0.
Mascarenhas, Lazzarotti A Fo, Vianna LC. A ciência e a RBCE em tempos de pandemia. Rev Bras Ciênc Esporte. 2020;42:e2001. http://dx.doi.org/10.1590/rbce.42.e2001.

Mascarenhas, Lazzarotti A Fo, Vianna LC. RBCE, mais um ciclo se encerrando e novos desafios. Rev Bras Ciênc Esporte. 2019;41(4):341-2. http://dx.doi.org/10.1016/j. rbce.2019.10.001.

Revista Movimento. Fórum de Editores de Periódicos Científicos da Área de Educação Física. Carta de Porto Alegre [Internet]. Porto Alegre: UFRGS; 2019 [citado 2021 Fev 22]. p. 1-5. Disponível em: https://www.ufrgs. br/revistamovimento/documentos/carta_porto_alegre. pdf

Rocha L. Comitê Consultivo do SciELO divulga documento em apoio à pesquisa brasileira [Internet]. Botucatu: ABEC; 2020 [citado 2021 Fev 22]. Disponível em: https://www. abecbrasil.org.br/novo/2020/11/comite-consultivodo-scielo-divulga-documento-em-apoio-a-pesquisabrasileira/ 